\title{
Subclinical eating disorder symptoms and positive vs. negative affect in high school students: the mediating role of self-regulation
}

\author{
Sybilla Blasczyk-Schiep ${ }^{A, B, C, D, E}$, Kaja Adamczewska ${ }^{E, F}$, Kaja Funez Sokoła ${ }^{E, F}$ \\ SWPS University of Social Sciences and Humanities, Wroclaw, Poland
}

BACKGROUND

Subclinical symptoms of eating disorders (ED) appear early, and adolescents still represent a specific risk group. Are there strategies of self-regulation which can protect adolescents against severe symptoms? We investigated differential mediators between subclinical eating disorder symptoms and negative vs. positive affect in adolescents.

\section{PARTICIPANTS AND PROCEDURE}

Data were collected twice. Adolescents (ages 17-18, $N=98$ ) filled in the Eating Disorders Inventory (EDI-2), the Volitional Competences Questionnaire (VCQ), the Personality Style and Disorders Inventory (PSDI) and the Positive and Negative Affect Schedules (PANAS). We postulated two different serial multiple mediation models originating in eating disorders, one leading to negative affect (through depressive personality style and self-motivation) and the other leading to positive affect (through self-regulation competences: self-relaxation and self-motivation).

\section{RESULTS}

The serial multiple mediation models were confirmed, with the postulated variables serving as mediators of positive and negative affect. In addition to body dissatisfaction, there were two additional predictors for positive affect (ineffectiveness and social insecurity) and five predictors for negative affect (drive for thinness, bulimia, perfectionism, interoceptive awareness, asceticism).

\section{CONCLUSIONS}

These experiences of eating disorders are associated with affect, through self-regulation of emotion (self-motivation), which along with depression or self-relaxation leads to either a decrease in the negative affect or an increase in the positive affect. Self-regulation is an important factor in preventing eating disorders and protecting the overall emotional well-being in high school students.

\section{KEY WORDS}

eating disorders; self-regulation; affect; action vs. state orientation

CORRESPonding AUthor - Sybilla Blasczyk-Schiep, Ph.D., SWPS University of Social Sciences and Humanities, 30 Ostrowskiego Str., 53-238 Wroclaw, Poland, e-mail: schiep@t-online.de AUthors' Contribution - A: Study design - B: Data collection - C: Statistical analysis - D: Data interpretation . E: Manuscript preparation · F: Literature search · G: Funds collection

TO CITE THIS ARTICLE - Blasczyk-Schiep, S., Adamczewska, K., \& Funez Sokoła, K. (2019). Subclinical eating disorder symptoms and positive vs. negative affect in high school students: the mediating role of self-regulation. Current Issues in Personality Psychology, 7(2), 120-131. 


\section{BACKGROUND}

It is well known that symptoms of eating disorders (ED) appear early; however, especially adolescents still represent a specific risk group. According to the BELLA-Study $23 \%$ of adolescents between 14 and 17 years old self-reported eating disorder behaviors (Herpetz-Dahlmann, Wille, Hölling, Vloet, \& Ravens-Sieberer, 2008) which should not be compared to eating disorders in their appropriate sense. These findings confirm a former study showing that $20 \%$ of maturing girls experience subclinical eating problems giving symptoms of bulimia behaviors such as self-induced vomiting and unhealthy diet (Graber, Tyrka, \& Brooks-Gunn, 2003). The study carried out by Nishizawa et al. (2003) by means of the EAT-26 Questionnaire on Japanese adolescents aged 15-17 years showed that $11.2 \%$ of girls and $2.4 \%$ of boys experience subclinical eating disorder symptoms. Around $40 \%$ of all anorexia diseases refer to the early and middle adolescent stage whereas bulimia nervosa occurs in middle and late adolescence (Hoek, 2006).

Eating disorders affect young adults and adolescents all over the world, and countries that are higher or lower developed. The statistics show that in Poland (Ziółkowska, 2005), $0.5-1 \%$ of adolescents and $0.2-0.8 \%$ of adults suffer from anorexia. Specialists prove that the problem is currently affecting children as young as 9 years old. Research and statistics show that bulimia is more common than anorexia; it can affect $1.1-8 \%$ of the population of women. Even $1 / 3$ of patients are in a chronic condition.

Thus, adolescents may be recognized as an at-risk group particularly vulnerable to eating disorder occurrence, which might suggest that this age group should be provided with particular protection, prevention and control of the development of eating disorders. It has been proved that eating disorders include such behaviors as dietary restraint, binge eating and self-induced vomiting different from the clinical picture of an eating disorder in the severity, and not in the type of the symptoms. Several authors have suggested that disordered eating behaviors occur on a continuum, with asymptomatic, unrestrained eating at one end and clinical eating disorders on the other (Dancyger \& Garfinkel, 1995; Graber et al., 2003). Numerous studies have found support for the validity of the eating disorder continuum (Dancyger \& Garfinkel, 1995; Graber et al., 2003). These studies attempted to investigate the risk factors for $\mathrm{ED}$, i.e. psychological distress, low self-esteem, neuroticism (Tylka \& Subich, 1999), depression (Dancyger \& Garfinkel, 1995), perfectionism and affect lability (Levander et al., 2016), and body dissatisfaction (Tuschen-Caffier, Vögele, Bracht, \& Hilbert, 2003; Vocks, Wachter, Wucherer, \& Kosfelder, 2008; Forbes et al., 2012; Blasczyk-Schiep, Sokoła, Fila-Witecka, \& Kazén, 2016; Czepczor, Kościcka, \& Brytek-Matera, 2016).
The predictive role of body dissatisfaction for eating disorders in adolescents and young adults is well investigated. Blasczyk-Schiep et al. (2016) showed that "negative body and self-esteem was related to the ambitious/narcissistic personality style in a nonclinical population of young fashion models and controls". Other authors showed in a sample of Polish adolescents that females reported significantly greater dissatisfaction with their appearance than their male counterparts and significantly greater media pressure to change their body shape. However, men reported higher values on internalization of the athletic-ideal body shape than women. In both groups (female and male) body dissatisfaction was related to body mass index. The authors indicate that it is necessary to create effective programs to increase awareness of body image among people in late adolescence (Czepczor et al., 2016).

Symptoms of eating disorders are related to negative affect, fear of gaining weight and body dissatisfaction. Body dissatisfaction is a growing phenomenon in America, with at least $80 \%$ of girls and young women reporting being unhappy with their bodies (Forbes et al., 2012). The cognitive-affective component of a disordered body image is marked by dysfunctional thoughts and negative feelings towards one's own body (Vocks et al., 2008). Researchers found that women with eating disorders display negative emotions and cognitions to a greater extent when looking at their own bodies than do healthy controls (Tuschen-Caffier et al., 2003).

Negative emotions also play a huge role in provoking and sustaining binge eating. A lot of studies show that negative affect occurs prior to binge eating (Greno, Wing, \& Shiffman, 2000; Waters, Hill, \& Waller, 2001; Wegner et al., 2002). Despite dietary restraint and dysfunctional cognitive processes, emotional regulation is among factors sustaining eating disorders. Studies indicate that intensive emotional states as well as problems with their regulation and maladaptive regulation strategies (Gross, 2002; Svaldi, Griepenstroh, Tuschen-Caffier, \& Ehring, 2012), and problems with identification of emotions (Harrison, Sulivan, Tchantria, \& Treasure, 2010) are typical for eating disorders.

Fewer studies examine preventive factors of eating disorders and emotional well-being in adolescents. In this context, the following question would be interesting: If every fourth adolescent experiences subclinical symptoms of eating disorders (and only $1 \%$ of the population is suffering), what protects adolescents against the development of these symptoms and provides emotional well-being? However, researchers note that affect and affect regulation strategies connected with self-regulation abilities and action vs. state orientation (Kuhl, 2001; Legenbauer \& Vocks, 2014) play a significant role in eating disorders' treatment and their prevention. 
Affect and affect regulation in eating disorders are tested in different studies. Cardi, Leppanen, and Treasure (2015) in their meta-analysis quantified the effect of induced negative and positive mood on meal consumption in healthy participants and patients with eating and weight disorders. These findings support the relationship between negative affect and increased food intake, especially in restrained eaters and binge eaters. Preliminary evidence indicates that strategies to improve positive affect might be beneficial for people suffering from anorexia nervosa and bulimia nervosa. Kitsantas, Gilligan, and Kamata (2003) examined the self-regulatory strategies and subjective well-being of students who had recently been diagnosed with eating disorders, students in the group of risk, and individuals not diagnosed with eating disorders. As it was assumed, students with eating disorders reported a lower level of life satisfaction, more selfregulated strategies for keeping their weight at the same level, and higher levels of negative affect than reported by at-risk students or individuals with normal weight. At-risk students reported higher levels of self-regulation and negative affect than the students with normal weight.

Baumann, Kaschel, and Kuhl (2007) verified interactions between two types of affect in relation to emotional well-being and psychosomatic symptoms. As hypothesized, low sensitivity to positive affect and high sensitivity to negative affect were expected to become maladaptive when self-motivation and self-relaxation are low, respectively. The findings indicate that low sensitivity to positive affect (i.e. passive, depressive-like personality) was associated with reduced emotional well-being when self-motivation was low. It was also found that high sensitivity to positive affect (i.e. agreeable, histrionic-like personality) was associated with emotional well-being for participants low and high in self-motivation. When self-relaxation was low (self-regulation), high sensitivity to negative affect (i.e. passive, depressive-like personality) was associated with psychosomatic symptoms and not when self-relaxation was high. The findings support the distinction between affect sensitivity and affect regulation in relation to emotional well-being and appearance of psychosomatic symptoms. Researchers showed that affect regulation can be differentiated into two self-regulatory competences: selfmotivation and self-relaxation.

The ability to self-regulate one's feelings and thoughts is another important aspect of personality functioning in relation to eating disorders. Personality System Interaction Theory (PSI-Theory; Kuhl, 2001) differentiates the ability to reduce feelings of hopelessness or anxiety (i.e., self-relaxation) and to overcome feelings of listlessness or sadness (i.e., self-motivation). These self-regulatory abilities are assessed by two dimensions of state versus action orientation (Kuhl, 1994; Baumann et al., 2007). Failure related action orientation (AOF) is conceived of as the ability to reduce (downregulate) negative affect (self-relaxation) once it is aroused and to maintain or even increase self-access (self-determination) in the face of threatening and painful experiences. Decision-related action orientation (AOD) is conceived of as the ability to self-generate (upregulate) positive affect in the face of difficulties and problems (self-motivation) which should result in behavioral facilitation (i.e. striving and achieving one’s own goals) (Kuhl \& Kazén, 1999). Similarly, self-regulation can be differentiated into the ability to overcome a lack of positive affect (AOD, selfmotivation) and the ability to reduce negative affect (AOF, self-relaxation).

In this theoretical context, we can formulate two questions: Are there strategies of self-regulation which can protect adolescents against the severity of the symptoms and severity of negative affect (associated with the occurrence of ED symptoms)? Can, despite the reported symptoms of eating disorders, adolescents with competences of self-regulation feel and increase positive affect and relive the emotional well-being?

We postulate that ED symptoms, for example Body Dissatisfaction (BD), are positively associated with negative affect (NA). Eating disorders (e.g. BD) are associated with NA through depressive personality style (DPS), they increase negative affect and additionally ED (e.g. BD) are associated with selfmotivation (SM), which in parallel reduce negative affect. We assume that negative affect (NA) is mediated through both variables: depressive personality style (DPS) and self-motivation competences (SM). Finally, through this path with depressive personality style (DPS) and self-motivation (SM), the negative affect (NA) associated with eating disorders (ED, BD) will be reduced in the nonclinical adolescent sample.

Also, we postulate that ED symptoms (e.g. BD) are negatively associated with positive affect (PA). Additionally, we assume that emotional well-being (positive affect) is mediated through both self-regulatory competences: self-relaxation (SR) which reduces negative affect and self-motivation (SM) which activates positive affect. These two self-regulatory competences probably reduce symptoms of ED (e.g. BD) in adolescents and increase positive affectivity (PA). We assume that despite the symptoms of eating disorders, self-regulation increases and provides emotional well-being in adolescents.

In this study we carried out serial multiple mediation analyses (Hayes, 2012, 2013), which allow one to analyze a chain of multiple mediators between predictor and outcome variables. Specifically, we aimed to investigate in a nonclinical sample of adolescents 
(who are the most vulnerable age group to the occurrence of ED symptoms), the chain of variables starting with different aspects of reported eating disorder symptoms comparing two different pathways, one leading towards negative affect, and the second resulting in positive affect. Firstly, it was hypothesized that depression (DPS) and self-motivation (SM) would mediate the relationship between ED symptoms (e.g. BD) and negative affect (NA). In conclusion, the postulated serial multiple mediator model describes the following chain: $\mathrm{BD}>\mathrm{DPS}>\mathrm{SM}>\mathrm{NA}$. Secondly, it was hypothesized that the association between ED symptoms (e.g. BD) and positive affect (PA) would be mediated by self-relaxation (SR) and self-motivation (SM). In conclusion, our assumed serial multiple mediator model 2 describes the following chain: $\mathrm{BD}>\mathrm{SR}>\mathrm{SM}>\mathrm{PA}$.

\section{PARTICIPANTS AND PROCEDURE}

\section{PARTICIPANTS}

At Time 1 (T1) 98 adolescents (71.42\% were girls) participated in the study. They were 17 to 18 years old $\left(M=17.65, S D=0.47 ;\right.$ BMI $\left.M=22.7 \mathrm{~kg} / \mathrm{m}^{2}, S D=23.0\right)$.

Ninety-one individuals $(92.34 \%)$ took part in the study at Time 2 (T2) three months later. The study was conducted during school hours. Students were informed about the objectives and the procedure of the study. At T1 each participant voluntarily filled in a questionnaire. After three months at T2, students again filled in the same questionnaire (without PSDI). All participants provided their consent to participate in the study. The study was approved by the Institutional Review Board.

\section{SELF-REPORT MEASURES}

\section{Eating disorder symptoms}

Eating Disorders Inventory-2 (EDI-2; Garner, 1991) was used to assess symptoms of eating disorders. The Eating Disorder Inventory (EDI) comprises 91 questions, divided into eleven subscales. Each question is on a 6-point scale (ranging from always to never), rated $0-3$. The 11 subscale scores on the EDI are: Drive for Thinness, Bulimia, Body Dissatisfaction, Ineffectiveness, Perfectionism, Interpersonal Distrust, Interoceptive Awareness, Maturity Fears, Asceticism, Impulse Regulation, Social Insecurity. The most relevant EDI-2 scales for the research were the 8-item Body Dissatisfaction (BD) subscale, which measures individuals' attitudes, feelings and behaviors related to their bodies, Drive for Thinness (DT): an excessive concern with dieting, preoccupation with weight, and fear of weight gain, Bulimia (BL): episodes of binge eating and purging. The EDI-2 has been shown to have good construct validity in both clinical and non-clinical populations, as well as high internal consistency, in the present study for the Polish version (Cronbach's $\alpha$ between .79 and .89).

\section{Self-regulation}

Self-regulation competences were assessed with the Volitional Components Inventory (VCQ; Kuhl \& Fuhrmann, 1998) in the Polish adaptation (Blasczyk-Schiep, 2004). Responses to the items of this inventory are given on 4-point Likert scales. Scores of the subscales range from 0 to 12 . They include the following: (a) Self-relaxation (action orientation after threat or failure, AOF), which relates to self-regulation of negative affect. People low in selfrelaxation (state oriented) report uncontrollable rumination after failure or other aversive experiences, whereas people high in self-relaxation (action oriented) are able to disengage from such rumination whenever they want to focus on something else. (b) Self-motivation (action orientation related to demands, AOD), which relates to the recruitment of positive affect to carry out one's intentions in difficult or demanding situations. People low in selfmotivation (state oriented) need external help and encouragement to avoid procrastination, whereas people high in self-motivation (action oriented) are able to motivate themselves (i.e., upregulate positive affect) to enact their intentions. The Cronbach's $\alpha$ values for the Polish version of Self-relaxation and Self-motivation are .78 and .80 , respectively (Blasczyk-Schiep, 2004).

\section{Personality styles}

We applied the Personality Styles and Disorders Inventory (PSDI; Kuhl \& Kazen, 2009) in the Polish adaptation (Blasczyk-Schiep, 2004). The PSDI is a standardized and normalized measure designed to assess personality styles in the non-pathological range which are analogous to the personality disorders described in psychiatric diagnostic manuals, such as the DSM-5 (American Psychiatric Association, 2014). It was constructed on the basis of Personality Systems Interactions (PSI) theory (Kuhl, 2001), and on the symptoms described in the DSM-4 Axis II, related to personality disorders. The scales of the PSDI are (Style/disorder): Ambitious/narcissistic, Assertive/antisocial, Charming/histrionic, Conscientious/compulsive, Critical/ passive aggressive, Intuitive/schizotypal, Loyal/dependent, Optimistic/rhapsodic, Passive/depressive, Reserved/schizoid, Self-Critical/avoidant, Spontaneous/borderline, Unselfish/self-sacrificing, and Willful/ paranoid. Responses are given using a 4-point Likert scale. The most relevant PSDI-S scales for this research were personality styles with high sensitivity 
to negative affect: Passive/depressive (Style/disorder). Reliability of the scales (Cronbach's $\alpha$ for the Polish version lies between $\alpha=.74$ and $\alpha=.86$ ) (BlasczykSchiep, 2004).

\section{Affect}

Affect was assessed with the Positive and Negative Affect Schedules (PANAS; Watson, Clar, \& Tellegen, 1988). Participants are presented with a list of positive and negative emotions, and are asked to indicate the extent to which they are currently experiencing each emotion using a 5-point scale. The measure consists of two 10-item mood scales: positive affect (PA) - active, alert, attentive, determined, enthusiastic, excited, inspired, interested, proud, strong and 10-item for negative affect (NA) - afraid, scared, nervous, jittery, irritable, hostile, guilty, ashamed, upset, distressed. The PANAS is a widely used instrument in studies investigating state affect in a variety of time frames. Studies have confirmed good reliability of the PANAS, with average Cronbach's $\alpha$ of .87 for PA and .90 for NA, along with evidence of strong construct validity (Fajkowska \& Marszał-Wiśniewska, 2009).

\section{PROCEDURE}

High school students were recruited in two high schools in Poland and were asked to fill in the battery of questionnaires. Their participation was voluntary. The alleged purpose of the study was to investigate the factors related to their affect in association with eating disorder symptoms and self-regulation. Participants were asked questions about their age, weight and height. The adolescents answered the questionnaires in the following order: PANAS; VCQ, EDI-2, and PSDI at Time 1. After three months at T2, students again filled in the PANAS; VCQ, EDI-2. Completion of the survey took about 35-30 min.

\section{DATA ANALYSIS}

To examine our assumed serial multiple-mediator models, we applied the SPSS macro PROCESS developed by Hayes (2012). This macro includes a formal test of indirect effects using bootstrapping. In this study, bias-corrected bootstrap confidence intervals were calculated, based on 5000 bootstrap resamples. An indirect effect is statistically significant when the 95\% bootstrap confidence interval does not include zero (Hayes, 2013). As suggested by MacKinnon (2008), the independent variable, the mediator, and the dependent variable in the respective equations were measured at two different time points (T1 and T2) to establish temporal precedence.

\section{RESULTS}

Descriptive statistics and inter-correlations among the variables measured in this study are listed in Table 1. Almost all of the variables included in the two serial multiple regression analyses correlate significantly with each other. Note that Body Dissatisfaction correlates significantly with all mediator and outcome variables included in the two serial multiple regression analyses. Eating disorder symptoms (measured at T1 and T2) from EDI-2 (Drive for Thinness, Bulimia, Body Dissatisfaction, Ineffectiveness, Perfectionism, Interoceptive Awareness, Asceticism, Impulse Regulation, Social Insecurity) correlate significantly with Negative Affect (T1 and T2). The only exceptions are Interpersonal Distrust and Maturity Fears. High level of ED symptoms was strongly associated with high level of Negative Affect.

Eating disorders symptoms (Body Dissatisfaction, Ineffectiveness, Interoceptive Awareness, Impulse Regulation, Social Insecurity) correlate significantly with Positive Affect (T1 and T2). High levels of ED symptoms were associated with low level of Positive Affect. Additionally, high levels of self-regulatory competences (Self-relaxation and Self-motivation) were strongly associated with a low level of Negative Affect (T1 and T2) and high level of Self-motivation was strongly associated with high level of Positive Affect (T1 and T2). High level of Self-motivation and Self-relaxation was associated with low level of ED symptoms (Drive for Thinness, Body Dissatisfaction, Ineffectiveness, Interpersonal Distrust, Interoceptive Awareness, Social Insecurity, Impulse Regulation), which can be expected (see Table 1).

\section{TESTING THE MEDIATING ROLE OF SELF-REGULATION}

Results of the first serial multiple mediation model with Body Dissatisfaction (BD, T1) as a predictor, depressive personality style (DPS, T1) and Self-motivation (SM, T1) as mediators, and Negative Affect (NA, T2) as outcome, are shown in Table 2 and Figure 1. The results listed in Table 2 revealed a significant direct effect of BD (T1) on NA (T2; c1). Most importantly, the indirect effect involving all four variables (M2) was significant (i.e., the lower and upper limit CI do not include zero). This means that both DPS (T1) and SM (T1) serve as mediators of the relationship between BD (T1) and NA (T2), in that order. This is in line with the serial chain postulated in the first hypothesis. The other indirect effects (M1 and M3) were also significant (see Table 2). Noteworthy in Figure 1 is that the sign of the path from SM (T1) to NA (T2) is negative (b2 $=-0.64$ ), which means that SM (with depression) relates negatively to Negative Affect, as a protection factor, whereas DPS (T1) has the opposite sign in the 
Table 1

Descriptive statistics (means and standard deviations for EDI-2 predictor variables) and inter-correlations among the predictors (T1) and mediating variables (T1) and dependent variables ( $T 1$ and $T 2)$ of the study $(N=98)$

\begin{tabular}{|c|c|c|c|c|c|c|c|c|c|c|}
\hline & & $M$ & $S D$ & DPS & SR & SM & NAT1 & NAT2 & PAT1 & PAT2 \\
\hline 1. & DT & 18.11 & 8.52 & $.30^{*}$ & $-.26^{*}$ & $-.20^{*}$ & $.20^{*}$ & $.28^{*}$ & $-.16^{*}$ & $-.22^{*}$ \\
\hline & $B L$ & 12.83 & 5.93 & $.44^{* *}$ & $-.13^{*}$ & -.10 & $.27^{*}$ & $.25^{*}$ & $-.21^{*}$ & -.08 \\
\hline & BD & 29.92 & 11.32 & $.34^{*}$ & $-.27^{*}$ & $-.40^{*}$ & $.20^{*}$ & $.29^{*}$ & $-.30^{*}$ & $-.38^{*}$ \\
\hline 4. & I & 28.52 & 8.01 & $.66^{* *}$ & $-.29^{*}$ & $-.41^{* *}$ & $.40^{* *}$ & $.43^{* *}$ & $-.52^{*}$ & $-.40^{* *}$ \\
\hline 5. & $\mathrm{P}$ & 17.21 & 5.22 & $.25^{*}$ & -.10 & .02 & .18 & $.27^{*}$ & .05 & .17 \\
\hline & ID & 23.94 & 6.46 & .19 & -.17 & -.19 & .09 & .14 & $-.37^{*}$ & $-.35^{*}$ \\
\hline & IA & 25.93 & 8.45 & $.65^{* *}$ & $-.30^{*}$ & $-.26^{*}$ & $.35^{*}$ & $.44^{* *}$ & $-.32^{*}$ & $-.24^{*}$ \\
\hline & $M F$ & 28.92 & 6.71 & .19 & $-.20^{*}$ & $-.22^{*}$ & .16 & .01 & -.12 & -.09 \\
\hline & AS & 20.22 & 5.43 & $.41^{* *}$ & -.13 & -.11 & $.26^{*}$ & $.32^{* *}$ & -.05 & -.15 \\
\hline 10. & IR & 26.54 & 9.53 & $.66^{* *}$ & $-.34^{*}$ & $-.26^{*}$ & $.47^{* *}$ & $.38^{* *}$ & $-.30^{*}$ & -.14 \\
\hline 11. & SI & 26.71 & 6.52 & $.43^{* *}$ & $-.30^{*}$ & $-.43^{* *}$ & $.31^{*}$ & $.46^{* *}$ & $-.42^{* *}$ & $-.48^{* *}$ \\
\hline 12. & DPS & 4.76 & 2.71 & 1 & -.19 & $-.35^{* *}$ & $.47^{* *}$ & $.48^{* *}$ & $-.34^{*}$ & $-.28^{*}$ \\
\hline 13. & SR & 4.24 & 2.62 & $-.33^{*}$ & 1 & $.67^{* *}$ & $-.40^{*}$ & $-.33^{*}$ & $.33^{*}$ & .19 \\
\hline 14. & $\mathrm{SM}$ & 5.32 & 2.23 & $-.35^{*}$ & $.67^{* *}$ & 1 & $-.35^{*}$ & -.34 & $.54^{* *}$ & $.39^{*}$ \\
\hline
\end{tabular}

Note. DT - Drive for Thinness, BL - Bulimia, BD - Body Dissatisfaction, I - Ineffectiveness, P - Perfectionism, ID - Interpersonal Distrust, IA - Interoceptive Awareness, MF - Maturity Fears, A - Asceticism, I - Impulse Regulation, SI - Social Insecurity, DPS Depressive Personality Style, SR - Self-relaxation, SM - Self-motivation, NAT1 - Negative Affect at T1, NAT2 - Negative Affect at T2, PAT1 - Positive Affect at T1, PAT2 - Positive Affect at T2. ${ }^{*} p<.01,{ }^{* *} p<.001$ (2-tailed).

Table 2

Path coefficients and confidence intervals $(\mathrm{Cl})$ of the serial multiple mediation model from body dissatisfaction to negative affect $(N=98)$

\begin{tabular}{lccc}
\hline Path estimates & Coefficient (SE) & Lower limit Cl & Upper limit Cl \\
\hline (a1) BD (T1) > DPS (T1) & $0.08(0.02)^{* *}$ & 0.03 & 0.13 \\
(a2) BD (T1) > SM (T1) & $-0.06(0.01)^{*}$ & -0.09 & -0.02 \\
(a3) DPS (T1) > SM (T1) & $-0.19(0.07)^{* *}$ & -0.35 & -0.04 \\
(b1) DPS (T1) > NA (T2) & $0.96(0.25)^{* * *}$ & 0.45 & 1.47 \\
(b2) SM (T1) > NA (T2) & $-0.64(0.33)^{* *}$ & -1.32 & -0.02 \\
(c1) BD (T1) > NA (T2) & $0.18(0.06)^{* *}$ & 0.06 & 0.31 \\
(c1') BD (T1) > (DPS, T1) > (SM, T1) > NA (T2) & $0.05(0.06)$ & -0.07 & 0.18 \\
\hline Indirect effects & Effect (SE) & Lower limit Cl & Upper limit Cl \\
\hline TOTAL & $0.13(0.04)(\dagger)$ & 0.05 & 0.23 \\
(M1) D (T1) > DPS (T1) > NA (T2) & $0.08(0.03)(\dagger)$ & 0.02 & 0.16 \\
(M2) BD (T1) > DPS (T1) > SM (T1) > NA (T2) & $0.01(0.01)(\dagger)$ & 0.001 & 0.04 \\
(M3) BD (T1) > SM (T1) > NA (T2) & $0.03(0.02)(\dagger)$ & 0.002 & 0.10
\end{tabular}

Note. $95 \%$ confidence intervals are shown. They are based on 5000 bootstrap resamples. If both lower limit $\mathrm{Cl}$ and upper limit $\mathrm{Cl}$ do not include 0, the effect is significant. SE - standard error, BD - Body Dissatisfaction (EDI-2), DPS - Depressive Personality Style (PSSI), SM - Self-motivation (VCQ), NA - Negative Affect (PANAS). M1 to M3 - Indirect Mediation Effects. ( $\dagger$ ) Significant indirect effect, ${ }^{*} p<.05,{ }^{* *} p<.01,{ }^{* * *} p<.001$. 

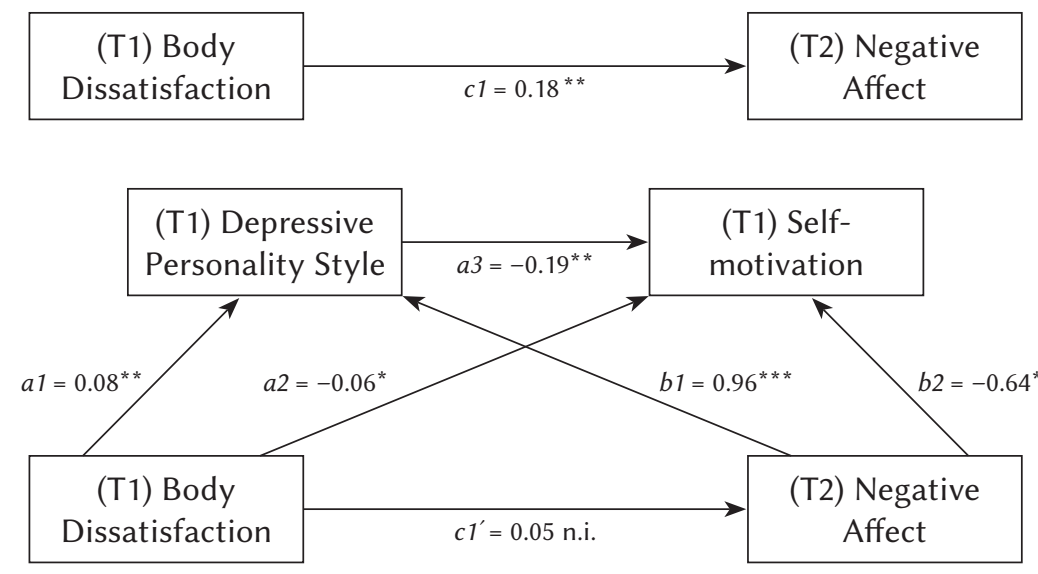

Note. The direct effect from Body Dissatisfaction to Negative Affect (c1) is significant. The indirect effect in the serial multiple mediation analysis chaining all variables is significant (see M2 in Table 2), indicating that both Depressive Personality Style and Self-motivation serve as partial mediators of the relationship between Body Dissatisfaction and Negative Affect. ${ }^{*} p<.05,{ }^{* *} p<.01$, $* * * p<.001$.

Figure 1. Associations between Body Dissatisfaction, Depressive Personality Style, Self-motivation, and Negative Affect in adolescents.

indirect model without SM as a mediating step. This result will be interpreted in the discussion.

Results of the second serial multiple mediation model with Body Dissatisfaction (BD, T2) as predictor, Self-relaxation (SR, T1) and Self-motivation (SM, T1) as mediators, and Positive Affect (PA, T2) as outcome are shown in Table 3 and Figure 2. The results listed in Table 3 revealed a significant direct effect of BD (T1) on PA (T2; c1). Consistent with model 2 the indirect effect involving all four variables (M2) was significant (i.e., the lower and upper limit CI do not include zero). This means that both SR (T1) and SM (T1) serve as partial mediators of the relationship between BD (T1) and PA (T1), in that order. This confirms the serial chain postulated in our second hypothesis. One other indirect effect (M3) was significant (see Table 3). That is, Self-motivation directly predicts Positive Affect (b2 $=0.91)$, whereas SR does not (see Figure 2).

Table 3

Path coefficients and confidence intervals $(\mathrm{Cl})$ of the serial multiple mediation model from body dissatisfaction to positive affect $(\mathrm{N}=98)$

\begin{tabular}{|c|c|c|c|}
\hline Path estimates & Coefficient (SE) & Lower limit $\mathrm{Cl}$ & Upper limit Cl \\
\hline (a1) BD (T1) > SR (T1) & $-0.06(0.01)^{*}$ & -0.05 & -0.01 \\
\hline (a2) $\mathrm{BD}(\mathrm{T} 1)>\mathrm{SM}(\mathrm{T} 1)$ & $-0.08(0.01)^{* *}$ & -0.11 & -0.03 \\
\hline (a3) SR (T1) > SM (T1) & $0.94(0.12)^{* * *}$ & 0.68 & 1.19 \\
\hline (b1) SR (T1) > PA (T2) & $0.05(0.52)$ & -1.32 & 0.42 \\
\hline (b2) $\mathrm{SM}$ (T1) > PA (T2) & $0.91(0.34)^{* *}$ & 0.23 & 1.59 \\
\hline (c1) BD (T1) > PA (T2) & $-0.19(0.04)^{* * *}$ & -0.28 & -0.09 \\
\hline$\left(\mathrm{c} 1^{\prime}\right) \mathrm{BD}(\mathrm{T} 1)>(\mathrm{SR}, \mathrm{T} 1)>(\mathrm{SM}, \mathrm{T} 1)>\mathrm{PA}(\mathrm{T} 2)$ & $-0.14(0.05)^{* *}$ & -0.24 & 0.03 \\
\hline Indirect effects & Effect (SE) & Lower limit $\mathrm{Cl}$ & Upper limit $\mathrm{Cl}$ \\
\hline Total & $-0.05(0.02)(\dagger)$ & -0.12 & -0.003 \\
\hline$(\mathrm{M} 1) \mathrm{BD}(\mathrm{T} 1)>\mathrm{SR}(\mathrm{T} 1)>\mathrm{PA}(\mathrm{T} 2)$ & $0.02(0.01)$ & -0.01 & 0.07 \\
\hline$(\mathrm{M} 2) \mathrm{BD}(\mathrm{T} 1)>\mathrm{SR}(\mathrm{T} 1)>\mathrm{SM}(\mathrm{T} 1)>\mathrm{PA}(\mathrm{T} 2)$ & $-0.03(0.01)(\dagger)$ & -0.07 & -0.07 \\
\hline (M3) BD (T1) > SM (T1) > PA (T2) & $-0.04(0.02)(\dagger)$ & -0.10 & -0.08 \\
\hline
\end{tabular}

Note. 95\% confidence intervals are shown. They are based on bootstrap 5000 resamples. If both lower limit $\mathrm{Cl}$ and upper limit $\mathrm{Cl}$ do not include 0 , the effect is significant. SE - standard error, BD - Body Dissatisfaction (EDI-2), RS - Self-relaxation, SM - Selfmotivation (VCQ), PA - Positive Affect (PANAS). M1 to M3 - Indirect Mediation Effects. (†) Significant indirect effect, ${ }^{*} p<.05$, ${ }^{* *} p<.01,{ }^{* * *} p<.001$. 

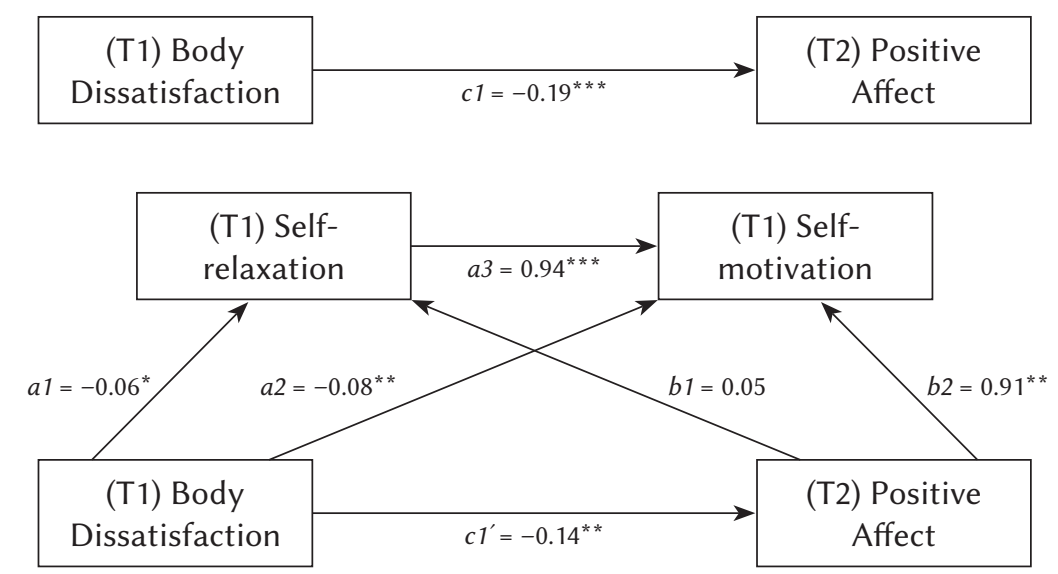

Note. The direct effect from Body Dissatisfaction to Positive Affect (c1) is significant. The indirect effect in the serial multiple mediation analysis chaining all variables is significant (see M2 in Table 3), indicating that Self-relaxation and Self-motivation serve as partial mediators of the relationship between Body Dissatisfaction and Positive Affect. ${ }^{*} p<.05,{ }^{* *} p<.01,{ }^{* * *} p<.001$.

Figure 2. Associations between Body Dissatisfaction, Self-relaxation, Self-motivation, and Positive Affect in adolescents.

\section{ALTERNATIVE MODELS}

Although the results are consistent with our expectations, we investigated exploratively whether other scales of the EDI-2 used as predictors would produce equivalent results. There were two additional scales (Ineffectiveness, Social Insecurity) which yielded significant results in predicting Positive Affect and five scales of EDI-2 (Drive for Thinness, Bulimia, Perfectionism, Interoceptive Awareness, Asceticism), which yielded significant results in predicting Negative Affect in our nonclinical adolescent sample.

(a) The Ineffectiveness (I) scale of the EDI-2, with Self-relaxation and Self-motivation as mediators, also predicted Positive Affect (cf. Table 3 and Figure 2). In the serial multiple mediation model the direct path from $\mathrm{I}>\mathrm{PA}$ was significant $(\mathrm{C} 1=-0.20$, $p<.001)$. In addition, the indirect path with two mediators $\mathrm{I}>\mathrm{SR}>\mathrm{SM}>\mathrm{PA}$ was significant (lower limit $\mathrm{CI}=-.1196$, upper limit $\mathrm{CI}=-.0075)$ as well as the indirect path with one mediator: $\mathrm{I}>\mathrm{SM}>\mathrm{PA}$ (lower limit $\mathrm{CI}=-.1501$, upper limit $\mathrm{CI}=-.0113$ ).

(b) The Social Insecurity (I, T1) scale of the EDI-2, with Self-relaxation and Self-motivation as mediators, also predicted Positive Affect (cf. Table 3 and Figure 2). In the serial multiple mediation model the direct path from SI (T1) > PA (T2) was significant $(\mathrm{C} 1=-0.34$, $p<.001)$. In addition, the indirect path with two mediators $\mathrm{SI}$ (T1) > SR $(\mathrm{T} 1)>\mathrm{SM}$ (T1) > PA (T2) was significant (lower limit $\mathrm{CI}=-.1107$, upper limit $\mathrm{CI}=-.0105$ ) as well as the indirect path with one mediator: SI (T1) $>\mathrm{SM}(\mathrm{T} 1)$ > PA (T2) (lower limit $\mathrm{CI}=-.1631$, upper limit $\mathrm{CI}=-.0143)$.

(c) The Drive for Thinness (DT, T1) scale of the EDI-2, with Depressive Personality Style (T1) and Self-motivation (T1) as mediators, also predicted
Negative Affect (cf. Table 2 and Figure 1). In the serial multiple mediation model the direct path from $\mathrm{DT}(\mathrm{T} 1)>\mathrm{NA}(\mathrm{T} 2)$ was significant $(\mathrm{C} 1=0.23, p<.01)$. In addition, the indirect path with two mediators DT (T1) > DPS (T1) > SM (T1) > NA (T2) was significant (lower limit $\mathrm{CI}=.0022$, upper limit $\mathrm{CI}=.0609$ ) as well as the indirect path with one mediator: DT (T1) $>$ DPS (T1) > NA (T2) (lower limit CI = .0348, upper limit $\mathrm{CI}=.2373)$.

(d) The Bulimia (BL, T1) scale of the EDI-2, with Depressive Personality Style (T1) and Self-motivation (T1) as mediators, also predicted Negative Affect (cf. Table 2 and Figure 1). In the serial multiple mediation model the direct path from BL (T1) > NA (T2) was significant $(\mathrm{C} 1=0.31, p<.01)$. In addition, the indirect path with two mediators BL (T1) > DPS (T1) > SM (T1) $>$ NA (T2) was significant (lower limit CI $=.0056$, upper limit $\mathrm{CI}=.1161)$ as well as the indirect path with one mediator: BL (T1) > DPS (T1) > NA (T2) (lower limit $\mathrm{CI}=.0840$, upper limit $\mathrm{CI}=.4123)$.

(e) The Perfectionism (P, T1) scale of the EDI-2, with Depressive Personality Style (T1) and Self-motivation (T1) as mediators, also predicted Negative Affect (cf. Table 2 and Figure 1). In the serial multiple mediation model the direct path from $\mathrm{P}(\mathrm{T} 1)>\mathrm{NA}(\mathrm{T} 2)$ was significant $(\mathrm{C} 1=0.37, p<.01)$. In addition, the indirect path with two mediators $\mathrm{P}$ (T1) > DPS (T1) > SM (T1) $>$ NA (T2) was significant (lower limit CI $=.0055$, upper limit $\mathrm{CI}=.1072)$ as well as the indirect path with one mediator: P (T1) > DPS (T1) > NA (T2) (lower limit $\mathrm{CI}=.0370$, upper limit $\mathrm{CI}=.2073)$.

(f) The Interoceptive Awareness (IA, T1) scale of the EDI-2, with Depressive Personality Style (T1) and Self-motivation (T1) as mediators, also predicted Negative Affect (cf. Table 2 and Figure 1). In the serial multiple mediation model the direct path from 
IA (T1) > NA (T2) was significant $(\mathrm{C} 1=0.39, p<.001)$. In addition, the indirect path with two mediators IA (T1) > DPS (T1) > SM (T1) > NA (T2) was significant (lower limit $\mathrm{CI}=.0001$, upper limit $\mathrm{CI}=.1182$ ) as well as the indirect path with one mediator: IA (T1) $>$ DPS (T1) > NA (T2) (lower limit CI = .0049, upper limit $\mathrm{CI}=.3243)$.

(g) The Asceticism (A, T1) scale of the EDI-2, with Depressive Personality Style (T1) and Self-motivation (T1) as mediators, also predicted Negative Affect (cf. Table 2 and Figure 1). In the serial multiple mediation model the direct path from A (T1) > NA (T2) was significant $(\mathrm{C} 1=0.42, p<.001)$. In addition, the indirect path with two mediators A (T1) > DPS (T1) > SM (T1) $>$ NA (T2) was significant (lower limit CI $=.0025$, upper limit $\mathrm{CI}=.1200)$ as well as the indirect path with one mediator: A (T1) > DPS (T1) > NA (T2) (lower limit $\mathrm{CI}=.0622$, upper limit $\mathrm{CI}=.3811$ ).

Finally, it should be mentioned that exchanging the mediators to predict Positive Affect (i.e., SR \& SM) or Negative Affect (i.e., DPS \& SM), respectively, did not yield significant results with any EDI-2 scales (DT, BL, I, P, IA, A, SI or SI) used as predictor in the serial multiple mediator models.

\section{DISCUSSION}

The serial multiple mediation models tested in our study showed that there are different paths leading to positive and negative affect in adolescents. In our first model the two mediator variables leading to negative affect were depressive personality style and self-motivation. These two variables served as complete mediators of the effect, as shown in Table 2 and Figure 1.

Concerning our main hypotheses in dealing with symptoms of eating disorders, we found that ED symptoms from the EDI-2 scales such as Body Dissatisfaction, Drive for Thinness, Bulimia, Perfectionism, Interoceptive Awareness, Asceticism promote deficits in stability of mood, which together with depressive personality style lead to increased negative affect in adolescents. Symptoms of ED in adolescents are negatively associated with self-regulation competences (self-motivation), which downregulate negative affect. Also the indirect paths between ED, depression, self-motivation and negative affect showed that depressive symptoms in relation with self-motivation decrease negative affect. Analysis of these pathways can lead us to the following conclusions. The adolescents with ED symptomatology and body dissatisfaction experience only negative affect when they have depressive symptoms, but at this moment, when they employ and use their self-motivation competences, they can down-regulate their negative affect.

The affective component of a body dissatisfaction or disordered body image, marked by dysfunctional thoughts and negative feelings towards one's own body, has been empirically verified (Tuschen-Caffier, 2003; Vocks et al., 2008; Legenbauer \& Vocks, 2014). The association between depression and ED symptoms has similarly been empirically verified (Dancyger \& Garfinkel, 1995; Levender et al., 2016). Self-regulated strategies for managing weight, life satisfaction, and higher levels of negative affect in college women with eating disorders and a healthy group were investigated in another study (Kitsantas et al., 2003). An interesting result is that in our group of healthy adolescents the ED symptom (i.e. body dissatisfaction) loses its predictive role in relation to the negative affect (including in the presence of depressive PS) if a mediator is self-regulation (self-motivation). Self-motivation is an ability to upregulate positive affect in a difficult situation and demanding circumstances. The results suggest that adolescents have healthy and effective self-regulatory competences, that reduce the negative affectivity and symptoms of the eating disorder. This result is similar to the findings of Baumann et al. (2007). The results indicate that high sensitivity to negative affect (i.e., passive depressive-like personality) was only associated with psychosomatic symptoms in patients and the healthy group when the ability to self-regulate one's feelings and thoughts was low, and not when the ability to self-regulate was high.

In consonance with our second model, the two mediator variables leading to positive affect were self-relaxation (failure-related action orientation) and self-motivation (decision-related action orientation). These two variables served as partial mediators of the affect, as shown in Table 3 and Figure 2. The direct path between SR and PA was not significant, which means that the disposition toward self-relaxation does not suffice to experience positive affect. Only when this disposition makes contact with a high level of self-motivation do the adolescents experience emotional well-being.

In the relation between ED symptoms and positive affect the mediation role was shown only by both self-regulatory competitions: self-relaxation and self-motivation. The indirect paths between ED, selfrelaxation, self-motivation and positive affect were significant. The results showed that ED symptoms (EDI-2 scales: Body Dissatisfaction, Ineffectiveness and Social Insecurity) in relation to self-relaxation and self-motivation increase positive affect. In order to maintain positive affect and emotional well-being, adolescents with ED symptoms must use two competences of self-regulation: self-relaxation and self-motivation. The mediation results indicate that eating disorder symptoms in adolescents (i.e. Body Dissatisfaction, Ineffectiveness and Social Insecurity) do not reduce emotional well-being when the adolescents have good self-regulatory abilities: self-relaxation and self-motivation. These results are compatible 
with those of Baumann (2007); the results indicate that high self-regulation (self-motivation) was associated with emotional well-being (irrespective of participants' initial sensitivity to positive affect) in psychosomatics patients and the non-clinical group. Other studies affirm the role of self-regulation in prevention of eating disorders, especially obesity (de Jong-Meyer et al., 1999; Campos-Uscanga, GutiérrezOspina, Morales-Romero, \& Romo-González, 2016). The authors state that self-regulation should be an essential component in the strategies for obesity prevention that must include orientation towards healthy eating and physical activity behaviors. The role of self-regulation in treating other psychological disorders such as anxiety or depression has been well proven (Hautzinger, 1994; Kuhl, 2001).

Action orientation is associated with ability of emotion regulation and probably play an important role in prevention of eating disorders (Legenbauer \& Vocks, 2014). Action orientation is conceived of as the ability to self-regulate positive and negative affect (Kuhl, 1994; Baumann et al., 2007), that is how quickly a person is able to leave an affective state once it is aroused (in contrast to affect sensitivity, i.e. neuroticism, anxiety, that is, how quickly a person enters an affective state). According to the PSI Theory of Kuhl $(1994,2001)$, for example, a person with body dissatisfaction or restraint eating will not get an eating disorder or remain in a negative mood when being able to downregulate negative affect. This person, even if they are socially insecure or not satisfied with their own body, will still feel emotional well-being, because they can motivate themselves and in their difficult social situations can gain something positive (self-motivation) or they can relax themselves well (self-relaxation).

One practical implication of our findings can be seen in the early assessment of individual differences in the two forms of emotion regulation distinguished here (i.e., self-relaxation and self-motivation). Moreover, our findings suggest a different focus of intervention depending on which of the two pathways applies to an individual. Failure-related action orientation suggests focusing on strengthening the ability to downregulate negative (i.e., self-relaxation) affect, whereas decision-related (prospective) action orientation suggests intervention focusing on developing the ability to upregulate positive affect when confronted with demanding daily tasks (i.e., development of self-motivation). The topic of self-regulation and eating disorder symptomatology and their relations to mental health with regard to clinical group should be verified in future studies. The adaptive role of self-regulation in non-clinical groups seems to be well-documented. The role of self-regulation in the motivation and efficacy of the treatment of anorexia and bulimia nervosa appears to be interesting for future study.
The present results, although consistent with our main predictions, have some limitations. First, further investigations involving sequential multiple mediation models leading to positive vs. negative affect, respectively, should use when possible a longitudinal design with an experimental measure of affect. A longitudinal, experimental design would require a much higher investment of time and resources. Second, body dissatisfaction and the other scales of ED are based on self-report about eating behavior. Those reports may be susceptible to biases. It would be recommendable for future studies to have a thirdperson perspective (e.g., relatives or friends) or other objective measures of eating symptomatology and emotional well-being, to examine the degree of agreement with the subjective report of the patients. Finally, the results were obtained with a particular large sample of adolescents (i.e. healthy adolescents from the risk groups and with an eating disorder). Before one can claim universality of the findings, future studies should be carried out in different countries to examine the transcultural validity of the serial multiple mediation models examined.

\section{References}

Baumann, N., Kaschel, R., \& Kuhl, J. (2007). Affect sensitivity and affect regulation in dealing with positive and negative affect. Journal of Research in Personality, 41, 239-248. doi: 10.1016/j. jrp.2006.05.002

Blasczyk-Schiep, S. (2004). Selbssteuerung und Suizidrisiko [Self-regulation and suicidal risk] (pp. 88-102). Bern: Peter Lang.

Blasczyk-Schiep, S., Sokoła, K., Fila-Witecka, K., \& Kazén, M. (2016). Are all fashion models susceptible to dysfunctional cognitions about eating and body image? The moderating role of personality styles. Eating and Weight Disorders, 21, 211-220. doi: 10.1007/s40519-015-0228-6

Campos-Uscanga, Y., Gutiérrez-Ospina, G., MoralesRomero, J., \& Romo-González, T. (2016). Self-regulation of eating and physical activity is lower in obese female college students as compared to their normal weight counterparts. Eating and Weight Disorders, 22, 311-319. doi: 10.1007/s40519-016-0338-9

Cardi, V., Leppanen, J., \& Treasure, J. (2015). The effects of negative and positive mood induction on eating behaviour: A meta-analysis of laboratory studies in the healthy population and eating and weight disorders. Neuroscience Biobehavioral Review, 57, 299-309). doi: 10.1016/j.neubiorev.2015.08.011

Czepczor, K., Kościcka, K., \& Brytek-Matera, A. (2016). Społeczno-kulturowe postawy wobec własnego wyglądu i niezadowolenie z ciała u kobiet i mężczyzn w okresie późnej adolescencji: badania wstępne [The sociocultural attitudes towards 
appearance and body dissatisfaction among late adolescence: pilot study]. Polskie Forum Psychologiczne, 21, 364-377.

Dancyger, I. F., \& Garfinkel, P. E. (1995). The relationship of partial syndrome eating disorders to anorexia nervosa and bulimia nervosa. Psychological Medicine, 25, 1019-1025.

de Jong-Meyer, R., Schmitz, S., Ehlker, M., Greis, S., Hinsken, U., Sonnen, B., \& Dickhöver, N. (1999). Handlungsorientierte Interaktionsbeiträge in verschiedenen Therapien: Prozeßsteuerung und Erfolgsrelevanz [Action-oriented contributions to interaction in various therapies: process control and success relevance]. Zeitschrift für Kilnische Psycholologie, Psychiatrie und Psychotherapie, 47, 172-190.

Fajkowska, M., \& Marszał-Wiśniewska, M. (2009). Właściwości psychometryczne Skali Pozytywnego i Negatywnego Afektu - Wersja Rozszerzona (PANAS-X). Wstępne wyniki badań w polskiej próbie [Psychometric properties of the Positive and Negative Affect Scale - Extended Version (PANAS-X). Preliminary results of tests in the Polish sample]. Przeglad Psychologiczny, 52, 355-388.

Forbes, G. B., Jung, J., Vaamonde, J. D., Omar, A., Paris, L., \& Formiga N. S. (2012). Body dissatisfaction and disordered eating in three cultures: Argentina, Brazil, and the U.S. Sex Roles, 66, 677-694. doi: 10.1007/s11199-011-0105-3

Garner, D. M. (1991). Eating Disorder Inventory-2. Professional Manual. Odessa, FL: Psychological Assessment Resources.

Graber, J. A., Tyrka, A. R., \& Brooks-Gunn, J. (2003). How similar are correlates of difference subclinical eating problems and bulimia nervosa? Journal of Clinical Psychology and Psychiatry, 44, 262-273.

Greeno, C. G., Wing, R. R., \& Shiffman, S. (2000). Binge antecedents in obese women with and without Binge Eating Disorder. Journal of Consulting and Clinical Psychology, 1, 95-102.

Gross, J. J. (2002). Emotion regulation: affective, cognitive, and social consequences. Psychophysiology, 39, 281-291. doi: 10.1017.S0048577201393198

Harrison, A., Sulivan, S., Tchantria, K., \& Treasure, J. (2010). Emotional functioning in eating disorders: attentional bias, emotion recognition and emotion regulation. Psychological Medicine, 40, 1887-1987.

Hautzinger, M. (1994). Action and state orientation in the context of psychopathological disorders. In J. Kuhl \& J. Beckmann (Eds.), Volition and personality: Action vs state orientation (pp. 209-213). Göttingen: Hogrefe.

Hayes, A. F. (2012). PROCESS: A versatile computational tool for observed variable mediation, moderation, and conditional process modeling. Retrieved from http://www.afhayes.com/public/process2012.pdf

Hayes, A. F. (2013). Introduction to Mediation, Moderation, and Conditional Process Analysis: A RegressionBased Approach. New York: The Guilford Press.
Herpertz-Dahlmann, B., Wille, N., Hölling, H., Vloet, T. D., \& Ravens-Sieberer, U. (2008). BELLA study group: Disordered eating behavior and attitudes, associated psychopathology and health-related quality of life: results of the BELLA study. European Child and Adolescents Psychiatry, 1, 82-91.

Hoek, H. W. (2006). Incidence, prevalence and mortality of anorexia nervosa and other Eating disorders. Currant Opinion in Psychiatry, 19, 389-394.

Kitsantas, A., Gilligan, T. D., \& Kamata, A. (2003). College Women with Eating Disorders: SelfRegulation, Life Satisfaction, and Positive/Negative Affect. Journal of Psychology, 4, 381-395. doi: 10.1080/00223980309600622

Kuhl, J. (1994). Action and state orientation: Psychometric properties of the action control scales (ACS-90). In J. Kuhl \& J. Beckmann (Eds.), Volition and personality: Action versus state orientation (pp. 47-59). Göttingen: Hogrefe.

Kuhl, J. (2001). Motivation und Persönlichkeit [Motivation and Personality]. Göttingen: Hogrefe.

Kuhl, J., \& Fuhrmann, A. (1998). Decomposing self-regulation and self-control: The Volitional Components Inventory. In J. Heckhausen \& C. S. Dweck (Eds.), Motivation and self-regulation across the life span (pp. 15-49). New York: Cambridge University Press.

Kuhl, J., \& Kazén, M. (1999). Volitional facilitation of difficult intentions: Joint activation of intention memory and positive affect removes Stroop interference. Journal of Experimental Psychology General, 128, 382-399. doi: 10.1037/0096-3445.128.3.382

Kuhl, J., \& Kazén, M. (2009). Das Persönlichkeits-Stilund-Störungs-Inventar (PSSI): Handanweisung, 2. Auflage [The Personality Style and Disorders Inventory (PSDI): Hand instruction, 2nd edition]. Göttingen: Hogrefe.

Lavender, J. M., Mason, T. B., Utzinger, L. M., Wonderlich, S. A., Crosby, R. D., Engel, S. G., Mitchell, J. E., Le Grange, D., Crow, S. J., \& Peterson, C. B. (2016). Examining effect and perfectionism in relation to eating disorder symptoms among women with anorexia nervosa. Psychiatry Research, 241, 267-272. doi: 10.1016/j.psychres.2016.04.122

Legenbauer, T., \& Vocks, S. (2014). Manual der kognitiven Verhaltenstherapie bei Anorexie und Bulimie [Manual of cognitive behavioral therapy for anorexia and bulimia]. Berlin: Springer.

MacKinnon, D. P. (2008). Introduction to statistical mediation analysis. Mahwah, NJ: Erlbaum.

Nishizawa, Y., Kida, K., Nishizawa, K., Hashiba, S., Saito, K., \& Mita, R. (2003). Perception of self-physique and eating behavior of high school students in Japan. Psychiatry and Clinical Neuroscience, 57, 189-196.

Svaldi, J., Griepenstroh, J., Tuschen-Caffier, B., \& Ehring, T. (2012). Emotion regulation deficits in eating disorders: a marker of eating pathology or 
general psychopathology? Psychiatry Research, 197, 103-111 doi: 10.1002/erv.2288

Tuschen-Caffier, B., Vögele, C., Bracht, S., \& Hilbert, C. (2003). Psychological responses to body shape exposure in patients with bulimia nervosa. Behavioral Research and Therapy, 41, 573-586.

Tylka, T. L., \& Subich, L. M. (1999). Exploring the construct validity of the eating disorder continuum. Journal of Consulting Psychology, 46, 268-276.

Vocks, S., Wachter, A., Wucherer, M., \& Kosfelder, J. (2008). Look at yourself: Can body image therapy affect the cognitive and emotional response to seeing oneself in the mirror in eating disorders? European Eating Disorders Review, 16, 147-154. doi: 10.1002/erv.825

Waters, A., Hill, A., \& Waller, G. (2001). Bulimics `responses to food cravings: Is binge-eating a product of hunger or emotional state? Behavior Research and Therapy, 39, 877-886.

Watson, D., Clark, L. A., \& Tellegen, A. (1988). Development and validation of brief measures of positive and negative affect: the PANAS scales. Journal of Personality and Social Psychology, 54, 1063-1070. doi: 10.1037/0022-3514.54.6.1063

Wegner, K. M., Smyth, J. M., Crosby, R. D., Wittrock, D., Wonderlich, S. A., \& Mitchel, J. E. (2002). An evaluation of the relationship between mood and binge eating in the neutral environment using ecological momentary assessment. International Journal of Eating Disorders, 30, 53-60. doi: 10.1002/ eat.10086

Ziółkowska, B. (2005). Anoreksja od A do Z. Podręcznik dla nauczycieli $i$ wychowawców [Anorexia from A to Z. Manual for teachers and educators]. Warszawa: Scholar. 